\title{
Los documentos cifrados en la Corte de Fernando VI (1746-1759)
}

\author{
Pedro Luis Lorenzo Cadarso **
}

\section{RESUMEN ABSTRACT}

Este artículo ofrece un estudio de la correspondencia cifrada a mediados del siglo xvIII desde una triple perspectiva: paleográfica, reconstruyendo los sistemas de codificación empleados; diplomática, explicando el proceso de expedición y

la estructura del discurso de estos documentos; e histórica, reflexionando sobre su empleo en la diplomacia borbónica. Se incluye también un breve estado de la cuestión acerca de la criptografía de la época y un repertorio de fuentes documentales cifradas.
This article is a study about the documentes writing in code during the whole reign of Fernando VI (17461759) of Spain. We make use triple view: The Paleography, the Diplomatic and the History. Its also included a brief introduction about the Cryptography and a catalogue of selected documents in code.

* Este trabajo se ha realizado en el marco del Proyecto de Investigación El tiempo de Ensenada, financiado por el Plan Nacional de Investigación, que dirige el Prof. J.L. Gómez URDÁNEZ, Catedrático de Historia Moderna de la Universidad de La Rioja, a quien agradezco su inestimable ayuda en la confección de este artículo.

*" Universidad de Extremadura. 


\section{ESTADO DE LA CUESTIÓN}

En las sofisticadas y cosmopolitas cortes del siglo XVIII, la política exterior y sus dos principales instrumentos, la guerra y la diplomacia, eran la reinas de todas las políticas ${ }^{1}$. A ellas dedicaban los reyes el grueso de su actividad personal, los hombres de mayor valía y cuantos recursos financieros y humanos estaban disponibles. Tanto la guerra como la diplomacia dependían, en gran medida, de la disponibilidad de información sobre aliados y enemigos, información que circulaba ordinariamente en el entorno del Ministerio de Estado - y en menor medida en el de Guerra, el de Marina y el de Indias - mediante una compleja red de correos que enlazaban los puestos diplomáticos del exterior y la red de espias introducidos en esos países con la Corte y las altas jerarquías de la Administración central.

Las valijas diplomáticas eran requisadas de ordinario en el extranjero, incluso en los países teóricamente aliados y, llegado el caso, hasta dentro del propio país por la pléyade de ribales políticos que todo dirigente arrastraba tras de sí. Por este motivo se recurría a las escrituras cifradas y a toda una serie de claves y contraseñas ${ }^{2}$ de una manera ordinaria. Las Cortes eran un hervidero de confidentes, diplomáticos y espías, cuyas actividades eran, si no consentidas, desde luego perseguidas sin tomar medidas represivas rigurosas: formaban parte, por así decirlo, del juego político en el que se desenvolvía la diplomacia.

Nuestro objetivo en este artículo, de todos modos, no es la vertiente histórica de esta faceta tan interesante de la historia del siglo XVIII, sino enfocar la correspondencia cifrada desde la perspectiva de la Paleografía y la Diplomática, esto es, mostrar los códigos secretos que se empleaban en esta época, desentrañar el proceso de expedición de los documentos cifrados y los rasgos formales que éstos presentan.

Paleográficamente son códigos escriturarios, luego competen a esta ciencia, al menos si la entendemos con la amplitud de miras que los debates teóricos recientes sobre la Paleografía como Historia de la Cultura

\footnotetext{
Vid., Cuenca TORIBıO, J.M., “La politica exterior española dieciochesca. Sus instrumentos: marina, ejército, diplomacia», Archivo Hispalense, $2^{a}$ época, L-LI. Sevilla, 1969; LóPEz CoRdóN, J.M., "Bases institucionales y sociales de la acción exterior española en el siglo xvIII", en Estado y fiscalidad en el Antiguo Régimen. Murcia, 1989. Una aportación fundamental es la de D. OzANAM, "La diplomacia de los primeros borbones (1714-1759)", en Cuadernos de Investigación Histórica, 6 , Madrid, 1982; "La política exterior de España en tiempo de Felipe V y Fernando VI", en Historia de España de Menéndez Pidal, t. XXIX-I. Madrid, 1985; y La diplomacia de Fernando VI. Correspondencia reservada entre don José de Carvajal y el duque de Huéscar, 1746-1749, Madrid, 1975.

2 Por ejemplo, el Marqués de la Ensenada era referenciado por sus colaboradores y espias como «El B" haciendo alusión al trazo de su rúbrica, que recordaba a dicha letra.
} 
Escrita invitan a hacer ${ }^{3}$. La imbricación de la escritura con lo político, con el ejercicio del poder en general, ya ha sido puesta de manifiesto en reiteradas ocasiones ${ }^{4}$, mostrándose cómo ciertas formas escriturarias han sido empleadas como auténticos emblemas de autoridad, y no sólo me refiero a los signos explícitos de poder, como los sellos, por ejemplo, sino incluso a la propia tipología de la escritura y a su ejecución concreta.

Las escrituras cifradas se relacionan con todo lo dicho, pero de una manera diferente: no son emblemas de autoridad, sino herramientas, instrumentos con los que ejercer el poder político de manera más eficaz. Son, en primer lugar, escrituras secretas, cuyo código sólo es conocido por un reducido grupo de personas situadas en las altas esferas de la Corte y sus servidores e informadores. Son también, en segundo lugar, escrituras de uso político exclusivamente, diseñadas para servir al poder garantizando el secreto, la confidencialidad.

Una página de la historia de la cultura escrita está compuesta, como hemos dicho, por lo que podría definirse como escrituras para grupos especiales. Como bien dice A. Gaur ${ }^{5}$, toda escritura podría plantearse como tal a un nivel teórico, dado que su código escriturario queda restringido a un determinado contexto social, cultural y cronológico. Sin embargo, probablemente esta afirmación introduzca un elemento de confusión innecesario, puesto que parece más apropiado considerar como escrituras para grupos especiales aquellas que, en un entorno cultural e histórico dado, sólo son conocidas por un sector restringido de la sociedad, no por un problema de analfabetismo stricto sensu, sino por tratarse de escrituras secretas o que dan respuesta a una necesidad funcional específica de un grupo concreto. Exclusivismo y secreto son pues dos de sus posibles caracteres.

Algunas responden a grupos sociales marginales, como la signografía empleada por bandas mafiosas ${ }^{6}$; otras a prácticas cabalísticas relaciona-

\footnotetext{
3 Véase, por ejemplo, CENCETTI, G., "Vechi e nuovi orientamenti nello studio della Paleografia”, La Bibliofilia, 50, 1950, págs. 4-23; PETRucci, A., "Storia della scritura e storia della societá", en III Cursos de Estudios Universitarios. Castellón, 1985; PEtquCCI, A., "La escritura tra ideologia e rappresentazione", en Storia dell'arte italiana, II, 1980, págs. 17-23; BARTOLI, A., Alfabetismo e cultura scritta nella storia della societá italiana. Perugia, 1978; o CARDONA, G.R., Antropología de la escritura. Barcelona, 1994.

4 Una de las últimas aportaciones es CASADO QuINTANILLA, B., "Poder y escritura en la Edad Media", Espacio, tiempo y forma, serie 3, $n^{2} 8,1995$, págs. 143-168; también puede consultarse Lorenzo Cadarso, P.L., "La escritura y el proceso social», Puertas a la lectura, n. 3, 1997, págs. 37-41.
}

5 Vid. Gaur, A., Historia de la escritura. Madrid, 1990, págs. 216-223.

6 Ibidem, págs. 222-223. 
das con ritos religiosos o sectas minoritarias, como la cábala hebrea; otras dan respuesta a necesidades funcionales, como la taquigrafía o el morse, por ejemplo, o a deficiencias físicas para acceder a los códigos ordinarios, como sucede con los ciegos ${ }^{7}$; también se conocen múltiples ejemplos de escrituras de este tipo vinculadas a determinadas formas de transmisión de la tradición oral, como los bastones mensajeros australianos o los pustahas de los hechiceros batak de Sumatra, y a grupos sacerdotales que monopolizaban el aprendizaje y el uso de la escritura, como ocurría con los glifos mayas ${ }^{8} \mathrm{o}$ las runas germánicas ${ }^{9}$.

En cualquier caso, existe un límite difuso entre escrituras secretas propiamente dichas y otras que, más que eso, son de uso socialmente restringido o bien escrituras inventadas. De ahí que sea pertinente emplear el concepto criptografía ${ }^{10}$, puesto que la tradición científica restringe su uso imponiendo dos condiciones: sólo se refiere a las escrituras con fines de comunicación secreta en el ámbito gubernamental, militar, diplomático o comercial; y, en segundo lugar, se trata de escrituras cifradas, esto es, que mediante una cifra o un código el texto común queda convertido en un criptograma ilegible para quien no conozca la clave empleada.

Suele distinguirse entre cifra y código, aunque la diferencia no siempre es muy nítida. Por cifra se entiende cuando la modificación del texto se hace empleando unidades textuales de similar longitud (una letra, dos, tres), mientras que en el código las unidades son de desigual longitud: desde una letra a una frase entera, pasando por sílabas, palabras, números, etc. Según esto, la criptografía del siglo XVIII sería un código, no una cifra.

En cuanto a las técnicas empleadas para el cifrado o codificación de un documento se conocen multitud de ejemplos, pero básicamente pueden reducirse a dos: el primero es la transposición o reordenación, es decir, que las letras, de acuerdo con el sistema que fije la clave, modifican su secuenciación ordinaria hasta hacer el documento ininteligible; el segundo se basa en la sustitución de los signos ordinarios por otros diferentes (ya sean letras, números o ideogramas), pero manteniendo la secuenciación original. La criptografía del siglo XVIII se correspondería pues con este último método. También cabe considerar una técnica criptográfica la ocultación mediante tintas invisibles u otros métodos.

\footnotetext{
7 Vid., Lorenzo Cadarso, P.L. y Sánchez SÁnchez, P., “Los códigos de lecto-escritura para ciegos: un siglo de renovación técnica”, Puertas a la Lectura, n² 5, 1998, págs. 49-53.

8 Vid. Robinson, A., Historia de la escritura. Barcelona, 1996, págs. 120-143.

- Vid. ANTONSEN, E.H., "Las runas: el más antiguo sistema de escritura germánico", en Senner, W. (comp.), Los orígenes de la escritura. Méjico, 1992, págs. 127-145.

10 Criptografía proviene del griego Kryptos (oculto) y graphein (escribir).
} 
La investigación de paleógrafos e historiadores ${ }^{11}$ ha demostrado el empleo de la criptografía desde al menos época egipcia y fueron de uso común en Grecia y Roma; de hecho, el primer tratado de criptografía conocido fue elaborado en el siglo III a.C. por Eneas "Tacticus". Se emplearon con cierta asiduidad durante toda la Alta Edad Media ${ }^{12}$, pero sería la Curia Papal la que, en el siglo Xv, desarrollaría los métodos más sofisticados para el cifrado de los documentos diplomáticos y, a partir de ellos, se extenderían por toda Europa ${ }^{13}$, incluida España ${ }^{14}$, desde las mismas fechas. Los métodos fijados en el siglo xv pervivirán, con leves modificaciones, hasta época contemporánea, cuando se comenzaron a aplicar formulismos matemáticos complejos y, sobre todo, técnicas mecanizadas para el cifrado.

El uso de criptogramas en España está documentado desde el siglo $x$ al menos, y continuándose su uso hasta el siglo XII, luego un lapso de tiempo, no sabemos si fruto de la caída en desuso de esta técnica o de la no conservación o descubrimiento de los diplomas. En esta primera época se conoce el empleo del método de sustitución por neumas, números romanos, letras griegas y conjuntos de puntos y líneas; también el de trasposición, escribiendo al revés las palabras o alterando su orden ${ }^{15}$.

1 Obras generales de referencia son COLLON, A., Étude sur la cryptographie. Bruselas, 1901; Lange, A. y SoudART, A., Traité de Cryptographie. París, 1925; MACBETH, J.C.H., Cryptography. Londres, 1922; MulLEF, A., Les écritures secrètes. Le chiffre, en "Que sais-je". París, 1982; SMITH, L.D., Cryptography, the science of secret writing. Londres, 1943. En castellano: GALENDE DIAZ, J.C., Criptografía. Historia de la escritura cifrada. 1995.

12 - Vid., para una visión general, RICHARD, J., «Cryptographie dans l’antiquite et le Haut Moyen Age", en L'Histoire et ses méthodes. París, 1961, págs. 616.632.

13 Pueden consultarse, entre otras obras, AIRAL.DI, G., Paleografia e criptografia nella storia genovese del quattrocento: Studi e documenti sur Genova e l'Oltramare. Génova, 1974; y Costamagna, G., Tachigrafia notarile e scritture secrete medioevali in Italia. Roma, 1968.

14 Véase la obra de Alcocer MARtin, M., "Criptografía española», Revista Histórica, 1, 1918, págs. 46-50; ibid., "Criptografía española", Revista de Archivos, Bibliotecas y Museos, XLII, 1921 págs. 628-640; Boletín de la Real Academia de la Historia, CV, 1934, págs. 336-340; y CVI, 1935, págs. 603-676; y el libro Criptografía española. Madrid, 1934. Otros trabajos iniciáticos en esta disciplina son RodrigueZ VILLA, A., "La escritura cifrada", Revista de Archivos, Bibliotecas y Museos, 11, 1872, págs. 129-134; y SALAS BOSCH, X. de, "Una lletra xifrada en català", Estudis Universitaris Catalans, 16, 1931, págs. 375-377. Trabajos más recientes son ARAgó Cabañas, A.M., "Una clau criptográfica del segle XV", Cuadernos de Arqueologia de la Ciudad de Barcelona. Barcelona, 12, 1968, págs. 171-176; CONDE y DELGADO DE MOLINA, R., "Una clave criptográfica relacionada con la Germania de Valencia", en Saitabi, 28, 1978, pags. 25-31; y CoRTÉs, J. y PONS, V., "Una clau criptogràfica d'Alfons el Magnànim per a la guerra amb Castella (1429)", Saitabi, 36, 1986, págs. 25-36.

15 Noticias sobre este período en MuÑoz y RIVERO, J., Paleografía visigoda. Madrid, 1919, págs. 85-88; Millares, A. (con la colab. De J.M. Ruiz Asencio), Tratado de Paleografía española. Madrid, 1983, Vol. I, págs. 290.294 
A partir del siglo XV, y aún antes para la Corona de Aragón ${ }^{16}$, los documentos cifrados son ya abundantes. Especialmente conocidos son los de la época de los Reyes Católicos ${ }^{17} \mathrm{y}$, en menor medida los del siglo XVI ${ }^{18} \mathrm{y}$ XVII ${ }^{19}$. La evolución, según el Prof. Galende ${ }^{20}$, sería un predominio de las claves esteganográficas en el siglo XV y comienzos del XVI, claves literales en el XVl; combinaciones de letras y números en el XVII; y puramente numéricas en el XVIII, que es la situación que nosotros nos encontramos.

\section{LA EXPEDICIÓN DE LOS DOCUMENTOS CIFRADOS}

La correspondencia cifrada se usaba habitualmente en las relaciones entre diplomáticos y entre éstos y el ministro de Estado, que era el jefe de la diplomacia, pero también por mucha gente de "servicio", como se decía eufemísticamente en la época. Por ejemplo, Jorge Juan, Antonio de Ulloa y otros viajeros-espias pagados por el gobierno. Lo hacían todos los embajadores y los ministros plenipotenciarios en las negociaciones políticas ${ }^{21}$ (tratados de paz, tratados comerciales, información relevante, noticias sensibles sobre la monarquía y los ministros, etc.). Cada vez que Bárbara de Braganza caía enferma, por ejemplo, el embajador francés duque de Duras escribía a la Corte pidiendo que se pensara en una princesa francesa para un segundo matrimonio con Fernando VI. Eran cartas muy peligrosas si alguien las hubiera "pescado" y puesto a los ojos del rey. No en vano, Duras pasó por sumamente imprudente ${ }^{22}$.

16 Vid., además de las obras citadas en la nota 15, PONS, J.M., “Característiques paleográfiques dels llibres notarials catalans fins el 1351", en VII Congreso de Historia de la Corona de Aragón, III, 1962, págs. 225-248.

17 Gracias a la obra de GALENDE DiAZ, J. disponemos de abundante información sobre este período: "Criptografía moderna: curioso cifrado entre el Obispo Diego de Muros y los Reyes Católicos", Boletín del Real Instituto de Estudios Asturianos, 144, 1994, págs. 385-398; "La correspondencia cifrada del embajador Lope de Soria", Hispania, LIl/181, 1992, págs. 493-520; "La escritura cifrada durante el reinado de los Reyes Católicos y Carlos V", Cuadernos de Estudios Medievales y Ciencias y Técnicas Historiográficas, 18-19, 1993-1994, págs. 159-178.

18 Devos, J. Paul, Les chiffres di Philippe I/ (1555-1598) et du Despacho Universal durant le XVle siècle, Bruselas, 1950; TRASSELLI, C., "Cifrari italiani e spagnuoli del XVI secole», en Archivi, 8, 1941, págs. 94-97.

19 GaLendE DiAZ, J.C., «Un diplomático español en la Europa del siglo XVI: Diego SAAVEDRA FAJARDO y su clave criptográfica con Felipe IV", Murgetana, 89, 1994, págs. 55-62; y DEVOS, J.P. Llaves de las cifras del siglo xvII. Lovaina, 1948.

20 Cfr., Galende, J.C., op. cit., pág. 102.

21 Para su empleo en la política colonial, vid. LOHMAN VILLENA, G., "Documentos cifrados indianos", Revista de Indias, XV, 1955, págs. 255-282. Una curiosa aplicación del cifrado en Moreyra, C.A., Los criptogramas de Santa Teresa. Córdoba (Argentina), 1964.

22 Véase Ozanam, D., "La política exterior de España...". Historia de España dirigida por Menéndez Pidal, t. XXIX, 1, págs. 334 y ss.; GómEZ URDAÑEZ, J.L., El proyecto reformista de Ensenada, 
El ministro y el oficial de la Secretaría encargado ${ }^{23}$, de manera habitual, cifran casi siempre todas las cartas oficiales, en especial las que van a embajadas en países no aliados o con los que hay algún contencioso importante, como fue el asunto de las Indias españolas y la presión inglesa sobre ellas durante todo el XVIII ${ }^{24}$. Se cifra más lo que va a Londres que lo que va a París, por ejemplo. A menudo se cruzan cartas personales, anodinas muchas veces, y en ellas se anuncia que en la cifrada que se enviará luego llegarán noticias de interés que no se pueden transmitir por vía ordinaria. Cuando el asunto es grave se emplean correos extraordinarios, a veces disfrazados -así se hizo con el correo que salió a Nápoles a dar la noticia de la muerte de Fernando VI-, y se escriben las cartas cifradas en billetes diminutos que los correos ocultan entre sus ropas.

En cada secretaría de despacho, especialmente en Estado, pero también en otros ministerios como Guerra, Indias o Marina, habia, junto al Secretario de Despacho, una serie de oficiales subdivididos en negociados - mesas, y, en la de Estado, traductores o "secretarios de lenguas" ${ }^{25}$. Uno o varios de éstos oficiales eran los encargados de escriturar y cifrar los documentos emitidos y, en su caso, descifrar los recibidos.

Cada secretaría tenía varios libros de claves. En Estado, había libros de claves para cada embajada y a veces incluso existían claves personalizadas diferentes para el embajador y el secretario. Por ejemplo, Ensenada tenía una para relacionarse con Ricardo Wall, embajador en Londres entre 1749 y 1754 , y otra para su correspondencia con Felix de Abreu, el secretario del embajador, que luego le sucedió en el cargo hasta 1760;

Lleida, 1996 y "La embajada de Duras en Madrid y la caída de Ensenada", en prensa en el número próximo de Hispania.

23 Para la Diplomática de la documentación cortesana del siglo xVIII, centrada además en el funcionamiento de una de las Secretarías de Despacho, la obra clave es Gómez Gómez, M., Forma y expedición del documento en la Secretaría de Estado y del Despacho de Indias. SeviIla, 1993.

24 Vid., por ejemplo, Garcia Baquero, A., Cádiz y el Atlántico, 1717-1778. Sevilla, 1976; Martinez Shaw, C., Cataluña en la carrera de Indias. Barcelona, 1981; Mijares Pérez, L., "Programa político para América del marqués de la Ensenada", Revista de Historia de América, 81. México, 1976; ORTEGa Medina, J., El conflicto anglo-español por el dominio oceánico (siglos xvil-xVIII). México, 1981; Pradells NAdAL, J., Diplomacia y comercio. La expansión consular española en el siglo XVIII. Alicante, 1992.

25 Para el funcionamiento administrativo de estas secretarias puede verse, LOPEZ CORDON, M.V., "La primera Secretaría de Estado: la institución, los hombres y su entorno", Revista de la Universidad Complutense. Madrid, 1980; un estudio enfocado desde la Diplomática es GómEZ GómEZ, M., Forma y expedición del documento en la Secretaría de Estado y del Despacho de indias. Sevilla, 1993, también la bibliografía que acompaña. Desde un punto de vista histórico, el mejor y más reciente estudio sobre la Corte en la época de Fernando VI es GómEz URDAÑEZ, J.L., El proyecto reformista de Ensenada. Lérida, 1996. 
pero aún dispuso de otra diferente para su correspondencia con Jorge Juan, al que envió a Londres en 1749 para espiar las construcciones navales ingiesas.

La necesidad de un código o de variar el existente por sospechas de que era conocido en las tramas del espionaje, la decidia el ministro en contacto con el oficial, el encargado de realizar una nueva cifra y su correspondiente libro de claves, que era enviado en sobre lacrado, con diferentes sellos, al destinatario. Éste respondía que había recibido el envio sin ser violado, por lo que ya podía establecerse la comunicación empleando el nuevo código. Así lo hizo, por ejemplo, Ensenada en 1749. Ensenada sospechaba que su correspondencia con Wall estaba siendo violada. En enero, el ministro envió a Londres el nuevo código en un sobre sellado con tres sellos de lacre con los que se sujetaba un cordón que ataba el librito de claves. Wall debería informar con seguridad de que no había sido violada para que Ensenada pudiera escribirle sobre «asuntos que le comunicaré en breve" y "para que Vs. y yo podamos tratar reservadamente", como así hizo el embajador ${ }^{26}$.

Era habitual la violación de correspondencia ${ }^{27}$, el asalto a los correos por sicarios en el camino ${ }^{28}$, la extracción de las cartas de sus sobres y su reposición luego mediante técnicas depuradas ${ }^{29}$. Los propios ministros, en momentos de tensión, se vigilan. Así ocurrió no sólo con Carvajal y Ensenada sino con estos dos y el marqués de Villarias, don Sebastián de la Cuadra, al que derribaron en 1746. El duque de Huéscar le escribía en cifra a Carvajal en diciembre de 1746 temeroso de que "Quadra (el marqués de Villarias) trabaja mucho para pescar alguno de mis pliegos para Ensenada, y este principio me obliga a cautelarme, porque intentará 10 mismo con las que vayan para ti" ${ }^{30}$. En ocasiones, los corresponsales de los altos dignatarios les dicen en sus cartas que ellos romperán las que reciban, eliminando así las pruebas de la correspondencia, para aumentar su posibilidad de recibir noticias interesantes y para mostrar su lealtad.

26 AHN, Estado, leg. 4277-3, Ensenada a Wall, 29 de enero 1749.

27 Cuando cae Ensenada en julio de 1754, el embajador en París sabe que ha llegado un correo oficial francés desde Madrid y lo comenta con Abermale, embajador inglés en la corte de Luis XV. Éste le dice que tal y como están las cosas le sorprende "cómo le han dejado pasar sin desvalijarle». AGS, Estado, leg. 4523. Masones a Wall, 19 de agosto de 1754.

28 Es un tema del que habla a veces el embajador Keene, que lo ve con toda normalidad. Véase Lodge, R., Private correspondence of sir Benjamin Keene. Cambridge, 1933.

${ }^{29}$ Sobre el tema del espionaje en España en el xvill realiza una tesis Cesary Taracha (de la Universidad de Lublin).

30 Huéscar a Carvajal, 19 de diciembre de 1746, en Ozanam, D., La diplomacia de Fernando VI..., pég. 113. 
Es muy probable que ni el ministro ni siquiera los secretarios de Despacho conociesen a fondo el código empleado, ésta era tarea de los subalternos, de los oficiales de la Secretaría. El procedimiento habitual era que el ministro dictase el texto y que el Secretario lo escriturase en forma de minuta o bien que el ministro lo escribiese en una nota que luego pasaba al Secretario. Luego uno de los oficiales, asesorado si era necesario por un traductor, cifraba el documento que, como veremos a continuación, normalmente carecia de cualquier tipo de validación, de manera que es probable que no volviese a pasar por las manos del Ministro y que fuera enviado al correo directamente por el Secretario.

Las cartas, que como veremos más adelante, no suelen llevar ni dirección ni intitulación, eran entregadas en mano por el correo a su destinatario, figura pues clave en todo el procedimiento, aunque con frecuencia ni siquiera su nombre nos es conocido. El marqués de la Ensenada y el resto de las altas jerarquias de la época llegaron a organizar sus propias redes de mensajeros al margen de la oficial, compitiendo a menudo entre ellos por ver quién conseguía hacer llegar sus mensajes antes y con mayor seguridad ${ }^{31}$.

Era también frecuente que el envío de los documentos cifrados se anunciase con anterioridad mediante una carta en el tono anodino de la cortesía dieciochesca y, del mismo modo, que su recepción y las sospechas de filtraciones que pudieran existir se comunicasen siguiendo similar procedimiento. También, en ciertas ocasiones, el texto cifrado se inserta dentro de la carta de cortesía.

La tradición de estos documentos es realmente compleja, tanto como lo anuncia su complejo proceso de expedición. La actio era, ya lo hemos dicho, una orden dictada verbalmente o comunicada en forma de nota de oficio por el responsable político, luego el secretario redactaba la minuta o borrador. El documento pasaba entonces a manos de los oficiales encargados de su cifrado ${ }^{32}$, siendo éste el que debemos considerar, a efectos diplomáticos, como el original, puesto que era el que realmente se enviaba

31 Sobre las rutas y los caminos puede consultarse RINGROSE, D.R., Los transportes y el estancamiento económico de España, 1750-1850. Madrid, 1972; y MADRAzo, S., El sistema de comunicaciones en España, 1750-1850. Madrid, 1984. O bien un interesante documento de época: Escribano, J.M., Itinerario español o guia de caminos para ir de Madrid a todas las ciudades y villas más principales de España; y para ire unas ciudades a otras; y a algunas Cortes de Europa. Madrid, 1758.

${ }^{32}$ Sobre el personal subalterno de las Secretarias puede consultarse también MARTínEz RoBLES, M., Los oficiales de las secretarías de Corte bajo los Austrias y los borbones, Alcala de $\mathrm{He}$ nares, 1987; asi como la clásica ESCUDERO, J.A., Los secretarios de estado y de despacho (14741724). Madrid, 1969. 
al destinatario. Sin embargo, y he aquí la paradoja, este documento no solía llegar a manos del destinatario, sino que previamente pasaba a uno de sus subalternos, que lo descifraba, primero en borrador, bien sobre el propio documento entre renglones, bien en hoja aparte. Luego lo pasaba a limpio, a texto común, retocándolo estilísticamente a menudo, y era esta copia la que realmente leía el destinatario.

\section{CARACTERES EXTERNOS}

En la conformación material de estos documentos primaba más el criterio de la funcionalidad de cara a garantizar su fácil ocultamiento por los correos que cualquier otra costumbre o uso diplomático en las Secretarías de Despacho borbónicas. El método a seguir en su envío, el transporte, era el que decidía el formato a emplear, optándose por la esquela o la cuartilla cuando iban a ser remitidos sin emplear el correo ordinario, lo cual exigía, o cuando menos recomendaba, que el documento pudiese ser ocultado con facilidad por el emisario.

En cualquier caso, tampoco cabe hablar de innovaciones propiamente dichas, puesto que los formatos empleados eran conocidos, e incluso podría decirse que usuales, en la Administración Moderna y en la correspondencia oficial y privada desde el siglo $x v{ }^{33}$ y aún antes. En esta época, los pliegos eran doblados una vez, in folio, dos veces, in quarto, siendo éstos los formatos empleados para los documentos expedidos al exterior o las comunicaciones procedentes del propio monarca, tres dobleces, in octavo, y una cuarta, esta vez longitudinal, que daba lugar a la esquela, técnicamente un dieciseisavo de folio ${ }^{34}$. Son estos dos últimos formatos los más comunes en la documentación cifrada, a menudo referenciados en las fuentes bajo el término genérico de billete.

Centrándonos pues en los formatos más usuales, el primer tipo era la mencionada esquela, escriturada no en horizontal, como era costumbre para permitir su cosido al incorporarla a los legajos, sino en vertical a una sola columna, aprovechándose —con el objeto de ahorrar volumen al

33 Un formulario de cartas para la correspondencia privada, que bien merecería un estudio diplomático detallado, es Juan VICENTE, Formulario y estilo curioso de escribir cartas misivas. Madrid, 1599. Se hizo una segunda edición, adaptándolo a la Real Pragmática de Tratamientos de Cortesía.

34 Véase Gómez GómEZ, M., Forma y expedición del documento en la Secretaria de Estado y del Despacho de Indias. Sevilla, 1993, págs. 250-254. Para la terminología, vid. MuzzERELLE, D. Vocabulaire codicologique. Múnich, 1981, págs. 39-42; y LEMAIRE, J., Introduction à la Codicologie. Louvain-La-Nouve, 1989, pág. 35. 
documento- ambas caras del papel y numerándose con arábigos, normalmente en el ángulo superior derecho, cuando la carta ocupaba más de una hoja. Este formato estaba especialmente diseñado para ser doblado múltiples veces hasta permitir ocultar el documento en cualquier pliegue de la ropa o del calzado.

El segundo tipo recurría a la cuartilla, formato usual en la correspondencia tanto oficial como privada. Al contrario de lo que sucede en éstas, los documentos cifrados suelen aprovechar al máximo el espacio, de manera que tiende a reducirse o incluso a desaparecer el margen de cortesía que se dejaba tradicionalmente a la izquierda de la página para permitir las anotaciones del receptor.

El tercero de los formatos es el folio, empleado con mayor frecuencia cuando el documento iba a ser enviado por el correo ordinario. No faltando casos en los que aparece algún signo de validación, normalmente limitado a la rúbrica, o incluso que la parte del texto que no contenia información confidencial esté escrita sin cifrar.

Se empleaba normalmente papel muy fino, al objeto de reducir el tamaño del documento y facilitar su ocultación. Otros caracteres formales tienen ese mismo objetivo, como es el empleo de letras sumamente pequeñas o reducir al máximo el espacio entre palabras y renglones.

\section{NOTAS SOBRE SU DISCURSO DIPLOMÁTICO}

Los documentos cifrados son, salvo excepciones, cartas que se ajustan a los usos tradicionales en la correspondencia privada o bien a las notas de oficio empleadas reiteradamente en la Administración absolutista desde el siglo XVI al menos. Se trata de unos documentos muy simples en su versión no cifrada: se abren con la invocación simbólica en el encabezamiento, la típica cruz; luego un formulismo de cortesía, que en ocasiones no llega a aparecer, pasando directamente al texto expositivo que, si ha lugar, se cierra con una petición, un dictamen o una orden, según sea el caso; el documento se cierra con una nueva fórmula de cortesía, muy abreviada, y la data tópica y crónica; al pie del texto aparece la suscripción del autor $y$, justo al final de la hoja, la dirección.

Sobre este modelo, los documentos cifrados introducen un número variable de alteraciones. Una de las más usuales es la ausencia de los tradicionales tratamientos de cortesía inicial y final, cosa que desde luego no ocurre siempre dado el extremado respeto por el protocolo que se sentía en la Corte dieciochesca. Otra modificación bastante común es la au- 
sencia de la data crónica y tópica. Mucho más reiterado es que se supriman dirección y suscripción o bien su sustitución por una versión simplificada del signado. Por ejemplo, Ensenada puede emplear su símbolo, muy parecido a una $B$ mayúscula, que usaba como rúbrica en su firma. Por eso, entre los amigos se le llama « $B$ ».

Por supuesto que otros elementos de validación usuales en la correspondencia oficial con el extranjero, como la utilización de papel presellado con el membrete de la Corona o los sellos de lacre, no aparecen en absoluto.

\section{LOS CÓDIGOS}

Los códigos se recogían, como ya hemos adelantado, en libros de claves, enviados desde la Corte a espías y embajadores con el mayor de los sigilos, dado que su interceptación resultaba, lógicamente, fatal. En cualquier caso, nunca la confianza en la confidencialidad de la correspondencia y en la eficacia de los códigos fue total, se modificaban con cierta frecuencia cada vez que había sospechas de que el oponente disponia de información que había sido cifrada, o incluso simplemente en momentos de tensión diplomática, situaciones en las que se reforzaban las medidas de seguridad.

Por otro lado, recurrir a motes, siglas o expresiones crípticas era también usual, dado que dificultaba la interpretación de los textos incluso cuando se violaba la correspondencia y se descifraban las cartas. Es muy frecuente, por ejemplo, que no se citase expresamente el asunto o materia sobre el que trataba la epístola, sino que se referenciase con expresiones como "la materia que nos ocupa o el trabajo que me trae por aqui". Todavía más lo es sustituir los nombres de persona por motes e incluso que éstos se mencionen mediante siglas. Véanse estos ejemplos de motes:

- José de Carvajal: «el tío no hay tal» (en alusión a su cabezonería).

- Marqués de la Ensenada: el «B», «el amigo», "el tinto». Al final de su ministerio, «el mogol» o «el gran mogol».

- El duque de Huéscar: «el tocayo» (por llamarse Fernando como el rey Fernando VI),

- Ricardo Wall: «el Dragón», «Cosme», «Leman».

-Villarias: «Chupacandiles», «Bastián», «Vélez», «el Vascuence». 
- El duque de Maceda ${ }^{35}$, «Mojarrilla».

- El infante Felipe, luego duque de Parma: "el serafín".

- Fernando VI: «Filis», «El dueño», «El amo», «el alcalde».

- Isabel de Farnesio: "Filosa».

- Duque de Sotomayor: "Cegato».

- Macanaz: «Viejón», «Viejo chocho».

Las claves empleadas eran conjuntos de dígitos variables entre uno y cuatro, siempre en arábigos, significando cada uno de ellos una letra, una sílaba o una palabra entera, sin que exista correspondencia entre el número de dígitos y el de letras: así, el conjunto 610 equivalía a la letra "S" y el 580 a la «r» en una esquela enviada en 1750 por Ordeñana; mientras que en otros conjuntos de tres, el 327 significaba «Estado" y el 652 "pliego". También se expresaban mediante dígitos los signos de puntuación, asi el 965 equivalía a una coma y el 966 a un punto. Otros dígitos habían de descifrarse por siglas, como el 800 , que significaba «V. S.», Vuestra Señoría.

Cada clave se separa de la siguiente mediante un punto, éste sin cifrar, o un guión; y a menudo también se subrayan individualizadamente. En algunos documentos, no en todos, se señalan los sangrados.

Son muy predominantes los grupos de tres dígitos, rondando el $80 \%$ en todas las claves. El uso de los grupos de uno es raro, dependiendo el uso de los de 2 y 4 de la clave empleada. Aparecen también casos de duplicaciones; por ejemplo, en la citada carta los dígitos 39 equivalen a "en", pero lo mismo significan los conjuntos 874 y 312 , sin duda para dificultar la tarea de descifrado en el caso de que el documento cayese en manos enemigas. Incluso habia palabras independientes que se cifraban mediante un único grupo de dígitos, así 103 significaba «a los».

En la elaboración del código, los grupos numéricos se indizaban de menor a mayor, comenzando por el 0; ordenándose por separado los conjuntos de uno, dos, tres y cuatro cifras. Por este motivo son predominantes los conjuntos que se inician por 0 y 1 en los de cuatro cifras ${ }^{36}$, aumentando progresivamente en los de tres, dos y una. Este sistema permitía componer el libro de claves indizando los dígitos, lo cual facilitaba la posterior labor de descifrado.

\footnotetext{
35 Gobernador de Madrid en 1746-48.

36 En la carta cifrada que Abreu envió a Ordeñana desde Londres en 1751 , el $100 \%$ de los conjuntos de 4 cifras se inician por 0 ó 1.
} 
En teoria, podrian existir un total de 11.110 combinaciones distintas -10.000 con grupos de $4 ; 1.000$ con grupos de $3 ; 100$ con grupos de 2 ; y 10 con dígitos sueltos-, suficientes para que cada grupo de dígitos equivaliera a una palabra completa y poder cifrar cualquier documento. En la práctica, como lo más común es que cada grupo equivalga a una sílaba, las posibilidades son extraordinariamente más amplias. Quizás por este motivo y para facilitar la tarea de cifrado y descifrado no se agotan, tal como hemos explicado, todas las posibilidades, sobre todo en cuanto a los grupos de 4 cifras.

Junto al empleo de motes, siglas y expresiones crípticas, el código en si contenía diversos mecanismos de seguridad adicional para dificultar su descifrado. Era frecuente, por ejemplo, la existencia de signos nulos, sin significado, tanto números sueltos como grupos completos; también lo era el empleo de signos que invalidaban al antecedente 0 al siguiente signo.

Existen dos modelos diferentes de documentos cifrados, en el primero, normalmente asociado al formato esquela, se cifra todo el documento, salvo la invocación, una cruz en el encabezamiento; en el segundo, aparecen sin cifrar las cláusulas de cortesía iniciales y, a veces, la data tópica y crónica y la suscripción; aunque reiteramos que los normal es que esta última se limite a una versión simplificada de la rúbrica habitual o que desapareciese por completo. Incluso hay algún caso en el que, como era usual en los oficios administrativos, se incluía la dirección al pie del documento.

El número de erratas es, dada la complejidad de los códigos, elevado: calculamos que, como mínimo, en torno al $10 \%$ de las palabras están mal escritas o son mal descifradas por el receptor. Este hecho se soslayaba cuando se transcribia el texto, que previamente había sido descifrado sobre el mismo documento (que era el procedimiento habitual), en la copia que el oficial enviaba al receptor, momento en el que se corregían los errores cometidos en el cifrado o en el descifrado del documento. A ello se le sumaba una redacción que huía de los formalismos estéticos en gran medida.

Como ejemplo de lo dicho, veamos una transcripción inicial hecha por el oficial de la Secretaría de Estado sobre la propia esquela en que se recibió el documento:

« [cruz] VS cuide VS de hacer entregar en propria mano a los correos sus pliegos, porque si se detieren en essa secretaria de estado, se puesder abrir, y saber lo que $V$ escribe si no vieni en numeros [siguen dos grupos de dígitos sin significado].» ${ }^{37}$.

37 Carta enviada por Ordeñana al marqués de Bondad Real, embajador en Parma, año 1750. Archivo General de Simancas, Suplementos, Leg. 175. 


\section{El original cifrado es éste que sigue:}

$+[\mathrm{cruz}]$ 800. 216. 160.800. 262./370. 199. 321. 320. 580. 39./677.674. 877. 519. 9. 103./238. 620. 950. 652. 610. 965./664. 751.937. 160. 942. 39. / 874. 312. 42. 936. 742. 31./ 442. 262. 327. 913. 741. 933. / 268. 93. 719. 590. 965. 680./735. 41. 49. 692. 870. 325. 243. 25. 754. 833. 312. 3./ 39. 588. 57. $725.872 .910 . / 898.966{ }^{38}$.

Sin embargo, el documento que realmente leía el receptor era, como hemos dicho, retocado por el oficial. Veámoslo en una carta cifrada de espionaje industrial que recibió el propio Agustín de Ordeñana al año siguiente desde la embajada de Londres ${ }^{39}$ :

"Mi señor y dueño y amigo [sin cifrar en el original]: Revolviendo papeles y librerias he encontrado dos libros que tratan de construcción de navios de todas partes con sus reglas para reducirlas a la práctica. Se me ha ofrecido que sería útil establecer en Cádiz, El Ferrol u otro conveniente puerto de España una academia de mozos carpinteros, en donde, a imitación de los guardias marinas, se estudiare y aprendiere el oficio de construir, cuyos estatutos y gobierno no sería difícil reglar. Si los constructores ingleses vienen a morir o desgraciarse será preciso recurrir otra vez al peligroso expediente de buscarlos aquí, cuando criándolos determinadamente para ello y con la ventaja de nuestras maderas, podremos quizá lograr ser algún día los constructores universales de Europa. Los dos libros mencionados podrían traducirse aqui, y que un maestro hábil en el oficio les leyese puntos todos los dias como se lee la Instituta Theologica y Philosophia ${ }^{40}$ en las Universidades. Entretanto que $\mathrm{Vm}$. se sirve lo que parece este pensamiento, procuraré yo adquirir más luces y si $\mathrm{Vm}$. lo juagase de poco fundamento, le suplico no lo comunique a S.E. ${ }^{41}$, porque tengo horror a pasar por proyectista. Londres, 30 de diciembre del 751.

Besa las manos de Vuestra Merced su más atento servidor. Don Félix de Abreu [rúbrica].

Al Señor Don Agustín de Hordeñana» ${ }^{42}$ [La data, la suscripción y la dirección van sin cifrar en el original]

38 Este documento presenta el formato de esquela que hemos descrito antes.

39 Sobre el entorno de este documento, es decir, el espionaje industrial español del xvII y su emisor, Abreu, pueden consultarse: Helguera QuiJANA, J., "Las misiones de espionaje industrial en la época del marqués de la Ensenada y su contribución al conocimiento de las nuevas técnicas metalúrgicas y artilleras a mediados del siglo xVII", Estudios de Historia de la Ciencia y de la Técnica, vol. II. Valladolid, 1988; LAFUENTE, A. y PESET, J.L., "Politica científica y espionaje industrial en Is viajes de Jorge Juan y Antonio de Ulloa (1748-1751)", Mélanges de la Casa de Velázquez, XVII. Madrid, 1981; PALACIO ATARD, V., "Las embajadas de Abreu y Fuentes en Londres, 1751-1761", Simancas, I, 1950.

40 Evidentemente, se trata de una ironia, puesto que sabida es la actitud despectiva que mantenian los ensenadistas hacia la Universidad tradicional.

41 Se refiere al marqués de la Ensenada.

42 Archivo General de Simancas, Secretaria de Marina, leg. 234. Este documento presenta el formato cuartilla que hemos descrito antes. 
El original cifrado, que se corresponde al tipo en que la cláusula de cortesía inical, la data, la dirección y la intitulación están sin cifrar, es éste que se sigue:

+ [cruz] Mi señor dueño y amigo. 047. 65. 0134. 106. / 69. 357. 0146. 208. 0139. 152. 161. 0141. 064. 096. 341. 11./361.69. 240. 357. 357. 152. 0141. 066. 152. 40. 390. 328. / 297. 239. 49. 115. 0179. 297. 30. 106. 46. 297. 387. 357. / 152. 267. 331. 152. 237. 0217. 047. 0245. 341. 0148. 226. / 047. 14. 0177. 0138. 226. 0135. 0265. 111. 0152. 0257. 30./092. 0174. 357. 39. 0152. 096. 164. 171. 335. 0134. 073. 62. 176. 69. 116. 354. 0163. 112. 014. 130. 042. 041. 093. 171./ 0144. 237. 056. 034. 72. 379. 297. 075. 226. 53. 16. / 116. 297. 312. 226. 297. 317. 222. 152. 122. 0203. 292./ 333. 146. 69. 358. 297. 226. 024. 170. 0276. 0179. 297. / 0135. 297. 302. 288. 354. 341. 252. 096. 30. 152. 112. 015. / 072. 50. 354. 226. 0152. 161. 226. 0267. 361. 29. 354. 20. 015. /[p. 2] 114. 090. 297. 239. 49. 81. 112. 0242. 146. 073. 50. / 389. 161. 0244. 036. 0152. 096. 226. 354. 1232. 0174. / 0134. 047. 0245. 288.

212. 0199. 239. 49. 115. 388. 072. 39. 331./34. 371. 030. 072. 106. 69. 013. 226. 370. 81. 0170. 353./186. 043. 0175. 042. 0152. 112. 0152.043. 0267. 0174. / 216. 047. 0241. 042. 096. 042. 0143. 105. 232. 208./ 0141. 0251. 216.076. 208. 354. 69. 331. 297. 067. 152. / 22. 0199. 226. 44. 112. 37. 0239. 0232. 357. 0194. 152. / 22. 0199. 226. 44. 112. 37. 0239. 0232. 357. 0194. 152. / 297. 333. 312. 30. 293. 310. 0148. 164. 20. 0192. 161.

37. 0135. 056. 29. 0276. 079. 297. 88. 341. 252. 297. / 243. 152. 112. 265. 292. 047. 371. 44. 0164. 152. 0194. 0186. / 043. 042. 0152. 042. 232. 302. 29. 354. 165. 0199. 239. / 49. 115. 388. 072. 171. 034. 103. 153. 0139. 152. 297. 19/ [p. 3] 172. 042.0171 .0146$.

0199. 357. 152. 0141. 066. 152. 0258. 0174. 140./226. 357. 152. 265. 292. 096. 0232. 390. 14. 0177. 01./226. 170. 161. 39. 53. 252. 072.48. 307. 59. 0134. 62. / 014. 090. 0139. 152. 0139. 28. 0152. 324. 29. 389./ 387. 357. 152. 0194. 152. 354. 341. 234. 0152. 0139. / 0135. 77. 335. 50. 0276. 0275. 361. 093. 0170. / 248. 226. 161. 0145. 363. 0194. 216. 132. 226. 69. / 0138. 52. 034. 103. 212. 294,072

069. 328. 387. 39. 4. 0152. 212. 042. / 056. 297. 0177. 0257. 0194. 40. 0139. 0148. 20. 0123. / 072. 331. 209. 153. 314. 112. 320. 0241.043. 043. 0161./227. 44. 096. 042. 0254.0200. 0165. 152. 113.161.212./2. 0194. 085, 152. 0187. 047. 297. 265. 233. 126. 53. / [p. 4] 93. 0258.387. 112. 0139. 0215. 0145. 0141 . 233. / 236. 0194. 235. 034. 39. 226. 0215. 076. 0123. 0140. / 0175. 268. 331. 29. 250. 364. 042. 041. 142. 226. / 146. 0150. 267. 320. 28. 115. 335. 152. 0276. Londres/30 de diziembre de 1751 .

Beso las Manos de Vuestra Merced. Su

más atento y obligado servidor

Don Félix de Abreu [signado]

Al Señor Don Agustín de Hordeñana [al pie de página] 
El libro de claves, del que siempre habrían de existir al menos dos copias, una en manos de la Secretaría que expedía el documentos y otra en la del agente o diplomático en el extranjero, incluía, además de las instrucciones técnicas para usarlo, un índice de letras, sílabas y palabras enteras ordenadas alfabéticamente y con su código correspondiente en columna al lado.

\section{SELECCIÓN DE FUENTES DOCUMENTALES CIFRADAS DE LA ÉPOCA DE FERNANDO VI}

Una buena parte de la correspondencia oficial con embajadas va en cifra. Se puede ver, por ejemplo, la que mantuvo Ricardo Wall con Londres o con París. Una selección:

- AGS, Estado, leg. 6.926, correspondencia del ministro Wall con Abreu (Londres).

- AHN, Estado, leg. 6512, Correspondencia del ministro Wall con Masones (París).

Muchas cartas de los grandes oficiales, sobre todo en las que se trasmiten favores y se cuentan rumores interesados, también van en cifra. Por ejemplo:

- AGS, Suplementos, leg. 175. Agustín Ordeñana (brazo derecho de Ensenada) con varios, por ejemplo, el marqués de Bondad Real (embajador en Parma), Ceballos, etc.

Muchas cartas a militares también van cifradas. Por ejemplo, se puede ver la correspondencia entre el marqués de la Ensenada y el marqués de la Mina, capitán general en las guerras de Italia y luego capitán general de Cataluña. Una selección:

- AGS, Guerra Moderna, Suplemento, leg. 603.

- AHN, Estado, leg. 4102 y leg. 2951.

Un ejemplo de correspondencia de un espía: Lo mejor del siglo son las cartas de Jorge Juan desde Londres ${ }^{43}$. Una selección:

43 Vid., Morales Hernández, J.L., "Jorge Juan en Londres", Revista General de Marina, 184, 
- AHN, Estado, leg. 4277 (noticias que da Ricardo Wall al Marqués de la Ensenada sobre Jorge Juan)

- AHN, Estado, leg. 4263 (noticias que da Abreu)

- AGS, Marina, leg. 712 (Instrucciones y cartas de Jorge Juan).

El XVIII es el siglo de la correspondencia epistolar. Todo el mundo escribe y guarda cartas. Los ministros y los altos jerarcas tenian que ser muy precavidos, por eso empleaban la cifra, pero muchas veces lo que hacían era mentir descaradamente a sabiendas del uso que podría hacerse de sus cartas. Por eso hay que tener cuidado con lo que se lee y no creerlo por el hecho de que se trate de documentos validados con todos formalismos diplomáticos al uso o sea autógrafo. El rectísimo Carvajal fingió que el tratado de Aquisgrán era lesivo para España y montó un gran teatro ante Fernando VI, y así el tratado ha pasado a la historia como un trágala impuesto por los franceses -así en todos los manuales-; pues bien, Carvajal estaba contentísimo del tratado. Mientras fingía estar dolido, escribía a sus amigos que el tratado les dejaba libres para "hacer maravillas» $y$ aún más: llegó a lamentar haber "pretado tanto arriba", es decir, haber pintado tan mal el tratado ante Fernando VI.

La figura del "recadista" es, como hemos dicho antes, fundamental en la correspondencia cifrada y en la diplomática en general. Es éste un sujeto de la mayor lealtad al ministro, que mantiene una correspondencia paralela con el fin de obtener noticias de todos los ámbitos. En el caso del marqués hubo dos: Ordeñana, más oficial, y Mogrovejo, más «sumergido". Cuando cayó el marqués, Wall ordenó inventariar su biblioteca y la de sus amigos en busca de papeles, cartas, que les comprometieran, por ejemplo, las que se cruzaban con Carlos de Nápoles. El inventario del recadista Mogrovejo es un ejemplo de cómo se almacenaba información en cartas, que se guardaban y archivaban ${ }^{44}$, y del papel que la correspondencia privada jugaba en la política dieciochesca ${ }^{45}$. Esto tenía el abate ensenadista en su casa, según el inventario que está en AHN, Estado, leg. 4.058:

44 Sobre el archivo de la Secretaría de Estado puede consultarse Pradelis y BaldaQui, J., "Los archiveros de la primera Secretaría de Estado (siglo xvIII)", Revista de Historia Moderna. Anales de la Univ. de Alicante, 6-7, 1988.

45 Estudios sobre la correspondencia privada en esta época, además de la citada de D. Ozanam, La diplomacia..., Gómez MOLLEDA, M.A., "El marqués de la Ensenada a través de su correspondencia íntima", en Eidos, 6. Madrid, 1957; LoDGE, R., Private correspondence of sir B. Keene. Cambridge, 1933; PÉREz PICÓN, C., "El pág. Isla, vascófilo. Un espistolario inédito", Miscelánea Comillas, 42. Santander, 1964; y 43, 1965. 
1. Un legajo "que se dice cartas de Roma de varios sujetos".

2. Cartas y papeles de Juan de Isla ${ }^{46}$.

3. Correspondencia de diversos sujetos.

4. Varios papeles.

5. Cartas y escrituras del conde de Maoy.

6. Noticias de la guerra por mar y tierra y copias de gacetas remitidas a varios sujetos.

7. Correspondencia con diversos sujetos.

8. Borradores de cartas italianas.

9. Correspondencia con el duque de Losada ${ }^{47}$.

10. Correspondencia con D. Roque Vallejo.

11. Correspondencia con D. Antonio Palombo desde Nápoles.

12. Traducción de la Historia del mundo.

13. Cartas del marqués de Revilla.

14. Gacetilla de noticias públicas.

15. Cuentas peculiares de su casa y familia.

16. Correspondencia con el conde de Cantiñano.

17. Cartas de varios sujetos estando en Italia.

18. Cartas cerradas para varios sujetos.

19. Impresos.

20. Cartas con la marquesa de la Torrecilla ${ }^{48}$, escritas desde los Sitios.

21. Cartas del duque de Salas ${ }^{49}$.

22. Cartas de París.

23. Memoriales y documentos de distintos sujetos.

46 Juan Fernández de Isla, el negociante más rico del norte de España, uno de los que construyó barcos para Ensenada desde la iniciativa privada (asientos). Acérrimo ensenadista. Vid., FERnANDEZ de VELASCO, F., “D. Juan Fernández Isla. Sus empresas y sus fábricas”, Revista de Archivos, Bibliotecas y Museos, V. Madrid, 1901

47 Un alto cortesano de isabel Farnesio, personaje muy amigo de Ensenada, del que se sospechaba relación con Nápoles. Una persona que era peligroso tratar.

48 Intima de Ensenada, camarera de la reina.

49 Íntimo de Ensenada, fue embajador en Nápoles por influencia de Ensenada, que mantuvo un cortejo con su mujer. 
24. Cartas de la duquesa de Ala y de la de Atry.

25. Cartas de la marquesa de Torrecuso y de la de Casteldorrios ${ }^{50}$.

26. Cartas de D. Fernando Jubino.

27. Cartas de Facundo Mogrovejo a su hermano.

28. Cartas de Nápoles de D. Tomás Pérez, oficial de la secretaría de Estado.

29. Cartas de D. Juan Gallo.

30. Varias gacetas de Italia.

31. Cartas de sobrinos y parientes.

32. Minutas de cartas familiares, "consistencia de la Familia de la casa real", etc.

33. Diversas cartas de España.

34. Diversas cartas de Nápoles.

35. Correspondencia desde los Sitios.

36. Cuentas particulares, abadía de Castrojeriz ${ }^{51}$, etc.

37. Diversos sujetos y noticias de Nápoles.

38. Cartas de Sicilia.

39. Cartas del duque de Montealegre, marqués de Scoti ${ }^{52}$, D. Sebastián Fernández de Elices y del marqués Fabio pertenecientes a las dependencias de este con su padre.

40. Cartas del marqués Traggiani ${ }^{53}$ de Nápoles.

41. Cartas de Andalucía.

42. Diversos.

43. Sueño político y varias poesias.

44. Cartas de Castrojeriz.

45. Cartas de París.

46. Cartas de d. Enrique Estelinguer.

47. Papeles del caballero de Malta D. Ernesto de la Fabra.

5n Camareras de la reina, intimas de Ensenada.

51. Mogrovejo, que vivía con Ensenada, era abate de Castrojeriz.

52 Scotti, napolitano al servicio de Carlos III en Nápoles y de Isabel Farnesio en La Granja.

53 Al servicio de Carlos III en Nápoles. 
48. Papeles varios y gacetas.

49. Cartas del marqués de Escoti, de D. Zenón de Somodevilla, del cardenal Valencia y de otros.

50. Cartas de D. Francisco de Las Cuentas, ministro de Sevilla.

51. Memoriales presentados al colegio de Venecia en tiempo de su embajada.

52. Minutas de cartas españolas.

53. Cartas de D. Juan Larrea.

54. Cartas de su hermano Ventura.

55. Cartas de Burgos.

56. Cartas del P. Antonio Rávago ${ }^{54}$.

57. Cartas de Indias.

58. Cartas de Florencia.

59. Cartas de D. Roque Vallejo de Nápoles.

60. Cartas del conde de Cantillana.

61. Varios impresos. 